\title{
VARIASI EKSTRAK ETANOL BIJI KEBIUL (Caesalpinia bonduc (L). Roxb) PADA FORMULASI SEDIAAN EMULSI M/A
}

\author{
Densi Selpia Sopianti*, Abdul Ricki, Aina Fatkil Haque \\ Akademi Farmasi Al-Fatah Bengkulu \\ *Email : dselpias@gmail.com \\ Artikel diterima: 01 September 2020; Disetujui: 28 Maret 2021 \\ DOI: https://doi.org/10.36387/jiis.v6i1.568
}

\begin{abstract}
ABSTRAK
Indonesia merupakan negara kepulauan yang kaya akan potensi alam yang sangat besar dalam penyedian bahan baku obat dan masih banyak tanaman yang belum tereksplor dan dimanfaatkan dengan baik. Biji kebiul (Caesalpinia bonduc (L). Roxb) merupakan tumbuhan obat secara empiris yang memiliki potensi besar untuk dimanfaatkan sebagai menangkal radikal bebas atau sebagai antioksidan karena senyawa yang ada dalam biji kebiul seperti alkaloid, flavonoid, saponin, dan steroid. Tujuan dari penelitian ini untuk membuat sediaan emulsi M/A dari Ekstrak Biji Kebiul yang diuji secara sifat fisiknya. Metode penelitian menggunakan metode eksperimental skala laboratorium dimana sampel yang digunakan adalah biji kebiul yang di ekstraksi dengan cara maserasi menggunakan etanol 96\%. Ekstrak dibuat dalam empat formula emulsi dengan konsentrasi masing-masing 10\%, 20\%, 30\%. Evaluasi Emulsi M/A memiliki hasil yang sempurna yang dilakukan adalah uji stabilitas (uji organoleptis, uji $\mathrm{pH}$ ), uji penampang mikroskop, uji sifat alir, uji viskositas, dan uji tipe emulsi. Hasil penelitian ini, biji kebiul dapat dibuat menjadi sediaan emulsi M/A. Variasi kadar Ekstrak biji kebiul (Caesalpinia bonduc (L). Roxb) yang memenuhi persyaratan evaluasi yaitu: uji organoleptis, uji pH, uji stabilitas, uji tipe emulsi, uji viskositas, dan uji penampang mikroskop.
\end{abstract}

Kata kunci: Biji Kebiul (Caesalpinia bonduc (L) Roxb), Emulsi, Uji sifat fisik.

\begin{abstract}
Indonesia is an archipelago state that is the nature have provides raw materials from medicinal plants, it is not yet used cause medicinal plants usually lived in the forests that have difficult access. Kebiul seed (Caesalpinia bonduc (L.) Roxb.) is an empirically medicinal plant belonging to the Caesalpiniaceae family which has great potential to be used as an prevent from free radicals or as an antoxidants cause kebiul seeds contains alkaloids, flavonoids, saponins, and steroids.The aims of this research to make a M/A emulsion substance. The sample that have been used in this study is kebiul seeds that have extracated by maceration and then evaporated with a waterbath. The extract was made in four formulas with each concentration 10\%, 20\%, 30\%. The evaluation of the M/A have perfect result which were done, stability test (odor, color and shape / texture and $\mathrm{pH}$ test) flow properties test, viscosity test, emulsion type test, and
\end{abstract}


microscope cross-section test. After analyzing the M/A emulsion substance the results from all of the evaluations that have been done from the 4 formulas, the kebiul seeds could be made into M/A Emulsion. Variation in contents of Caesalpinia bonduc (L.) Roxb extract which have the requirements evaluation, namely: organoleptic test, $p H$ test, stability test, emulsion type test, viscosity test, and microscope cross-section test.

Keywords: Kebiul seed (Caesalpinia bonduc (L.) Roxb), emulsion, physical properties test

\section{PENDAHULUAN}

Indonesia merupakan negara kepulauan yang akan potensi yang sangat besar dalam penyedian bahan baku tumbuhan obat karena sumber daya tersebut tersimpan di dalam hutan dan belum termanfaatkan dengan baik. Berdasarkan hasil penelitian, dari sekian banyak jenis tanaman obat, baru 20-22\% yang dibudidayakan, sedangkan sekitar $78 \%$ diperoleh melalui pengambilan langsung (eksplorasi) dari hutan (Nugroho, 2010).

Belakangan ini bumi semakin dipenuhi oleh radikal bebas sebagai senyawa atau bahan potensial yang mengancam kehidupan sel-sel dalam tubuh yang normal. Radikal bebas membahayakan kesehatan, radikal bebas dapat menyebabkan penyakit seperti kanker, jantung, artritis, diabetes, dan penyakit- penyakit degeneratif yang mana salah satu teori yang dianggap cukup signifikan penyebab penyakit tersebut yaitu reaksi radikal bebas. Berdasarkan teori ini, penyebab penyakit degeneratif (Sie, 2013).

Biji Kebiul (Caesalpinia bonduc (L) Roxb) merupakan tumbuhan obat dan secara turun temurun digunakan secara empiris yang merupakan famili Caesalpiniaceae yang memiliki potensi besar untuk dimanfaatkan sebagai menangkal radikal bebas atau sebagai antioksidan karena Kandungan senyawa yang ada dalam biji kebiul seperti alkaloid, flavonoid, saponin, dan steroid (Sopianti, 2017). Penelitian sebelumnya hasil skrining fitokimia biji kebiul (Caesalpinia bondul (L). Roxb) diperoleh dari fraksinasi aquadest dan n-heksana yang mengandung senyawa flavonoid dan fraksinasi etil asetat yang mengandung senyawa 
flavonoid dan saponin. Fraksinasi etil asetat yang mengandung senyawa flavonoid dan saponin. Sedangkan hasil uji menggunakan Kromatografi Lapis Tipis (KLT) pada fraksi aquadest, n-heksana dan etil asetat diperoleh hasil positif, yaitu flavonoid. Sehingga kebiul memiliki potensi yang sangat baik untuk pengobatan (Noviyanty, 2019).

Sediaan-sediaan farmasi yang bisa di uji terhadap hewan uji terkait dengan uji toksisistas yaitu dalam bentuk, emulsi, suspensi,sirup. Namun dalam kode etik hewan uji bentuk emulsi merupakan bentuk sediaan yang paling nyaman.

Berdasarkan latar belakang di atas, peneliti tertarik melakukan formulasi yang dapat diberikan ke hewan uji mencit (Mus Musculus) dari ekstrak aktif biji kebiul ( Caesalpinia bonduc (L). Roxb. Dengan bahan aktif ekstrak biji kebiul.

\section{METODE PENELITIAN}

Alat dan Bahan yang
digunakan dalam penelitian ini
adalah oven, alat maserasi, Rotari
evaporator, Timbangan analitik,

lumpang dan setemper Alat gelas (kaca arlogi, beker glass, cawan penguap, gelas ukur, erlemeyer, batang pengaduk, vial) sendok tandu, spatula, thermometer, viskometer Brookfield, Mikroskop, pH meter, Alat uji sifat alir. Bahan-bahan yang digunakan adalah: ekstrak biji kebiul, VCO, Tragakan, Sukrosa, Natrium Benzoat, Aquadest, metilen blue, sudan III, sediaan emulsi merek $\mathrm{x}$.

\section{Pengambilan Sampel}

Sampel yang digunakan adalah biji kebiul (Caesalpinia bonduc (L). Roxb) yang dibeli dari Pasar Kutau Kota Bengkulu Selatan yang sebelumnya diverifikasi di Laboratorium Universitas Bengkulu. Sampel dikeringkan dan dibuat simplisia untuk diekstraksi dengan metode maserasi menggunakan pelarut Etanol 96\% dan diuapkan di atas rotary evaporator hingga di dapat ekstrak pekat.

\section{Rancangan Formulasi Sediaan Emulsi Ekstrak Biji Kebiul}

Sediaan emulsi dibuat dalam 4 formulasi, dengan variasi masingmasing ekstrak biji kebiul adalah F0: 0\%, F1: 1\% F2: 20\% dan F3: 30\% Dapat dilihat pada tabel 1 . 
Tabel 1. Formulasi Sediaan Emulsi Ekstrak Biji Kebiul (Caesalpinia bonduc (L).

\begin{tabular}{ccccc}
\hline Bahan & \multicolumn{4}{c}{ Konsentrasi \% } \\
\cline { 2 - 5 } & F0 & F1 & F2 & F3 \\
\hline Ektrak kebiul & 0 & 10 & 20 & 30 \\
VCO & 15 & 15 & 15 & 15 \\
Tragakan & 2 & 2 & 2 & 2 \\
Sukrosa & 25 & 25 & 25 & 25 \\
Natrium benzoate & 0,1 & 0,1 & 0,1 & 0,1 \\
Aquades ad & 100 & 100 & 100 & 100 \\
\hline
\end{tabular}

Pembuatan Sediaan Emulsi Dari Ekstrak Biji Kabiul (Caesalpinia bonduc (L). Roxb) Menggunakan Metode Inggris

Timbang bahan sesuai dengan perhitungan, larutkan tragakan dalam mortir lalu basahi dengan air sebanyak 20x air kemudian gerus kuat sampai terbentuk mucilago tambahkan fase minyak (VCO) sedikit demi sedikit ad terbentuk korpus emulsi, setelah homogen tambahkan fase air (sukrosa, natrium benzoat dan aquadest) gerus ad homogen, masukan zat aktif (ekstrak biji kebiul), gerus ad homogen.

\section{Pengujian Sifat Fisik Emulsi}

\section{Uji Stabilitas}

Emulsi disimpan pada suhu dingin $4^{\circ} \mathrm{C}$, suhu ruangan $25^{\circ} \mathrm{C}$, dan suhu panas $40^{\circ} \mathrm{C}$ dengan melihat perubahan fisik (bau, warna, dan bentuk/tekstur sediaan) dan stabilitas $\mathrm{pH}$ (Ratnasari dan Handayani, 2018), yang diamati pada hari ke 0 ,
7, 14, dan 21 hari. Uji stabilitas emulsinya secara visual dan secara mikroskop (Febrina dkk, 2007).

\section{Uji Viskositas}

Pengukuran dilakukan menggunakan viskometer Brookfield pada pada suhu ruang $\left(27^{\circ} \mathrm{C}\right)$ menggunakan spindel no.4 pada kecepatan 100 rpm. Pengukuran dilakukan pada hari ke-0, 7, 14 dan 21 (Febrina, $d k k, 2007)$.

\section{3. ji Sifat Alir}

Ambil 10 sampai $15 \mathrm{ml}$ emulsi lalu dituangan diatas kaca kaca yang dengan sudut kemiringan $45^{\circ}$ lalu catat berapa waktu yang dibutuhkan emulsi untuk habis.

\section{Uji Tipe Emulsi}

Uji tipe emulsi dilakukan dengan sebanyak 3 gram yang telah dibuat dimasukkan dalam vial, kemudian ditetesi dengan larutan metilen biru. Jika larutan metilen biru segera terdispersi ke seluruh emulsi maka emulsinya memiliki tipe 
M/A. Ambil emulsi kemudian ditetesi dengan larutan sudan III, jika larutan sudan III segera terdispersi keseluruh emulsi maka emulsi memiliki emulsi A/M (Nurdianti danTuslinah, 2017).

\section{Uji Penampang Mikroskop}

Sediaan emulsi diletakkan pada kaca objek. Diamati dengan mikroskop dengan pembesar 10x10. Gambar yang diamati difoto dan diukur diameter globulnya. pengukuran partikel rata-rata dilakukan pada hari 0 dan 21 (martin, et al 1993).

\section{HASIL DAN PEMBAHASAN}

Berdasarkan hasil verifikasi tanaman kebiul yang dilakukan di laboratorium Biologi Universitas Bengkulu, menunjukan bahwa sampel yang digunakan adalah benar biji kebiul (Caesalpinia bonduc (L) Roxb) sesuai dengan Atlas Tanaman Obat Indonesia. Hasil verifikasi menyatakan bahwa tanaman yang digunakan dalam penelitian yaitu tanaman kebiul Famili Fabaceae, Ordo Fabales, Nama Ilmia Caesalpinia bonduc (L). Roxb, dan
Nama daerah kebiul yang disahkan dengan surat hasil verifikasi laboratorium No: 90/UN30.12LAB.BIOLOGI/PM/201 9.

\section{Hasil Evaluasi Stabilitas Emulsi} Ekstrak Biji Kebiul

Hasil pengamatan dilakukan bahwa dari ke 4 formulasi dan perbedaan suhu tidak ada perubahan baik dari Bau, Warna, dan Bentuk sediaan sehingga bisa dinyatakan stabil. Namun untuk uji $\mathrm{pH}$ terjadi kenaikan dan penurunan pada masing masing perbedaan suhu. Suhu yang paling stabil $\mathrm{pH}$ nya yaitu pada suhu $25{ }^{0} \mathrm{C}$ hal ini akan berpengaruh pada stabilitas penyimpanan. Selain itu juga pemeriksaan $\mathrm{pH}$ sediaan emulsi M/A kebiul bertujuan untuk memastikan bahwa $\mathrm{pH}$ sediaan emulsi M/A kebiul sesuai dengan $\mathrm{pH}$ normal saluran cerna, dimana kadar $\mathrm{pH}$ normal Untuk pemakaian oral adalah 5 sampai 7 untuk sediaan oral (Yulianto, Nugroho, Swandari, 2019). Apabila kadar $\mathrm{pH}$ sediaan kurang dari 5 akan dapat mengiritasi lambung karena bersifat asam. 
Jurnal Ilmiah Ibnu Sina, 6(1), Maret 2021, 11-20

p-ISSN: 2502-647X; e-ISSN: 2503-1902

Tabel 2. Hasil Uji Stabilitas pada suhu $4^{\circ} \mathrm{C}$ Formulasi Emulsi M/A Dari Ekstrak Biji kebiul (Caesalpinia bonduc (L). Roxb.

\begin{tabular}{|c|c|c|c|c|c|c|}
\hline \multirow{2}{*}{ Formulasi } & \multirow{2}{*}{$\begin{array}{c}\text { Parameter } \\
\text { Organoleptis }\end{array}$} & \multicolumn{4}{|c|}{ Pengamatan hari ke- } & \multirow{2}{*}{ Keterangan } \\
\hline & & $\mathbf{0}$ & 7 & 14 & 21 & \\
\hline \multirow{5}{*}{ F0 } & $\mathrm{pH}$ & 6 & 5 & 5 & 5 & Tidak Stabil \\
\hline & Warna & Putih & Putih & Putih & Putih & Stabil \\
\hline & Bentuk/ & Larutan & Larutan & Larutan & Larutan & \\
\hline & Tekstur & Kental & Kental & Kental & Kental & Stabil \\
\hline & $\mathrm{Bau}$ & Khas VCO & Khas VCO & Khas VCO & Khas VCO & Stabil \\
\hline \multirow{5}{*}{ F1 } & $\mathrm{pH}$ & 6 & 6 & 4 & 5 & Tidak Stabil \\
\hline & Warna & $\begin{array}{l}\text { Putih } \\
\text { Kekuningan }\end{array}$ & $\begin{array}{l}\text { Putih } \\
\text { Kekuningan }\end{array}$ & $\begin{array}{c}\text { Putih } \\
\text { Kekuningan }\end{array}$ & $\begin{array}{l}\text { Putih } \\
\text { Kekuningan }\end{array}$ & Stabil \\
\hline & Bentuk/ & Larutan & Larutan & Larutan & Larutan & \\
\hline & Tekstur & Kental & Kental & Kental & Kental & Stabil \\
\hline & Bau & Khas Kebiul & Khas Kebiul & Khas Kebiul & Khas Kebiul & Stabil \\
\hline \multirow{5}{*}{ F2 } & $\mathrm{pH}$ & 5 & 5 & 5 & 5 & Stabil \\
\hline & Warna & $\begin{array}{c}\text { Putih } \\
\text { Kekuningan }\end{array}$ & $\begin{array}{c}\text { Putih } \\
\text { Kekuningan }\end{array}$ & $\begin{array}{c}\text { Putih } \\
\text { Kekuningan }\end{array}$ & $\begin{array}{c}\text { Putih } \\
\text { Kekuningan }\end{array}$ & Stabil \\
\hline & Bentuk/ & $\begin{array}{l}\text { Kekuningan } \\
\text { Larutan }\end{array}$ & $\begin{array}{l}\text { Kekumimgan } \\
\text { Larutan }\end{array}$ & $\begin{array}{l}\text { Aekumingan } \\
\text { Larutan }\end{array}$ & $\begin{array}{l}\text { Aekumingan } \\
\text { Larutan }\end{array}$ & tol \\
\hline & Tekstur & Kental & Kental & Kental & Kental & Stabin \\
\hline & Bau & Khas Kebiul & Khas Kebiul & Khas Kebiul & Khas Kebiul & Stabil \\
\hline \multirow{5}{*}{ F3 } & $\mathrm{pH}$ & 5 & 6 & 5 & 4 & Tidak Stabil \\
\hline & Warna & Putih & Putih & Putih & Putih & Stabil \\
\hline & Bentuk/ & Kekuningan & Kekuningan & Kekuningan & Kekuningan & \\
\hline & Tekstur & Kental & Kental & Kental & Kental & Stabil \\
\hline & Bau & Khas Kebiul & Khas Kebiul & Khas Kebiul & Khas Kebiul & Stabil \\
\hline
\end{tabular}

Tabel 3. Hasil Uji Stabilitas pada suhu $25^{\circ} \mathrm{C}$ Formulasi Emulsi M/A Dari Ekstrak Biji Kebiul (Caesalpinia bonduc (L). Roxb.

\begin{tabular}{|c|c|c|c|c|c|c|}
\hline \multirow{2}{*}{ Formulasi } & \multirow{2}{*}{$\begin{array}{c}\text { Parameter } \\
\text { Organoleptis }\end{array}$} & \multicolumn{4}{|c|}{ Pengamatan hari ke- } & \multirow{2}{*}{ Keterangan } \\
\hline & & 0 & 7 & 14 & 21 & \\
\hline \multirow{5}{*}{ F0 } & $\mathrm{pH}$ & 5 & 4 & 4 & 4 & Tidak Stabil \\
\hline & Warna & Putih & Putih & Putih & Putih & Stabil \\
\hline & Bentuk/ & Larutan & Larutan & Larutan & Larutan & \\
\hline & Tekstur & Kental & Kental & Kental & Kental & Stabil \\
\hline & $\mathrm{Bau}$ & Khas VCO & Khas VCO & Khas VCO & Khas VCO & Stabil \\
\hline \multirow{5}{*}{ F1 } & $\mathrm{pH}$ & 5 & 4 & 4 & 4 & Tidak Stabil \\
\hline & Warna & $\begin{array}{c}\text { Putih } \\
\text { Kekuningan }\end{array}$ & $\begin{array}{c}\text { Putih } \\
\text { Kekuningan }\end{array}$ & $\begin{array}{c}\text { Putih } \\
\text { Kekuningan }\end{array}$ & $\begin{array}{c}\text { Putih } \\
\text { Kekuningan }\end{array}$ & Stabil \\
\hline & Bentuk/ & Larutan & Larutan & Larutan & Larutan & Stohil \\
\hline & Tekstur & Kental & Kental & Kental & Kental & Stabil \\
\hline & Bau & Khas Kebiul & Khas Kebiul & Khas Kebiul & Khas Kebiul & Stabil \\
\hline \multirow{4}{*}{ F2 } & $\mathrm{pH}$ & 5 & 5 & 5 & 5 & Stabil \\
\hline & Warna & $\begin{array}{c}\text { Putih } \\
\text { Kekuningan }\end{array}$ & $\begin{array}{c}\text { Putih } \\
\text { Kekuningan }\end{array}$ & $\begin{array}{c}\text { Putih } \\
\text { Kekuningan }\end{array}$ & $\begin{array}{c}\text { Putih } \\
\text { Kekuningan }\end{array}$ & Stabil \\
\hline & $\begin{array}{l}\text { Bentuk/ } \\
\text { Tekstur }\end{array}$ & Larutan & Larutan & Larutan & Larutan & Stabil \\
\hline & Bau & Khas Kebiul & Khas Kebiul & Khas Kebiul & Khas Kebiul & Stabil \\
\hline \multirow{3}{*}{ F3 } & $\mathrm{pH}$ & 5 & 5 & 4 & 5 & Tidak Stabil \\
\hline & Warna & Putih & Putih & Putih & Putih & Stabil \\
\hline & Bentuk/ & $\begin{array}{l}\text { KeKuningan } \\
\text { Larutan }\end{array}$ & $\begin{array}{l}\text { KeKuningan } \\
\text { Larutan }\end{array}$ & Larutan & Larutan & Stabil \\
\hline
\end{tabular}


Jurnal Ilmiah Ibnu Sina, 6(1), Maret 2021, 11-20

p-ISSN: 2502-647X; e-ISSN: 2503-1902

\begin{tabular}{ccccccc}
\hline \multirow{2}{*}{ Formulasi } & Parameter & \multicolumn{4}{c}{ Pengamatan hari ke- } & \multirow{2}{*}{ Keterangan } \\
\cline { 2 - 6 } & Organoleptis & 0 & 7 & 14 & 21 & \\
\cline { 2 - 6 } & Tekstur & Kental & Kental & Kental & Kental & Stabil \\
Bau & Khas Kebiul & Khas Kebiul & Khas Kebiul & Khas Kebiul & Kas \\
\hline
\end{tabular}

Tabel 4. Hasil Uji Stabilitas pada suhu $40^{\circ} \mathrm{C}$ Formulasi Emulsi M/A Dari Ekstrak Biji kebiul (Caesalpinia bonduc (L)Roxb.

\begin{tabular}{|c|c|c|c|c|c|c|}
\hline \multirow{2}{*}{ Formulasi } & \multirow{2}{*}{$\begin{array}{c}\text { Parameter } \\
\text { Organoleptis }\end{array}$} & \multicolumn{4}{|c|}{ Pengamatan hari ke- } & \multirow{2}{*}{ Keterangan } \\
\hline & & $\mathbf{0}$ & 7 & 14 & 21 & \\
\hline \multirow{5}{*}{ F0 } & $\mathrm{pH}$ & 5 & 5 & 5 & 4 & Tidak Stabil \\
\hline & Warna & Putih & Putih & Putih & Putih & Stabil \\
\hline & Bentuk/ & Larutan & Larutan & Larutan & Larutan & \\
\hline & Tekstur & Kental & Kental & Kental & Kental & Stabil \\
\hline & Bau & Khas VCO & Khas VCO & Khas VCO & Khas VCO & Stabil \\
\hline \multirow{6}{*}{ F1 } & $\mathrm{pH}$ & 5 & 4 & 4 & 4 & Tidak Stabil \\
\hline & Warna & Putih & Putih & Putih & Putih & Stahil \\
\hline & warna & Kekuningan & Kekuningan & Kekuningan & Kekuningan & Stabil \\
\hline & Bentuk/ & Larutan & Larutan & Larutan & Larutan & \\
\hline & Tekstur & Kental & Kental & Kental & Kental & Stabil \\
\hline & Bau & Khas Kebiul & Khas Kebiul & Khas Kebiul & Khas Kebiul & Stabil \\
\hline \multirow{6}{*}{ F2 } & $\mathrm{pH}$ & 5 & 4 & 5 & 4 & Tidak Stabil \\
\hline & Worn & Putih & Putih & Putih & Putih & Stahil \\
\hline & warna & Kekuningan & Kekuningan & Kekuningan & Kekuningan & Stabil \\
\hline & Bentuk/ & Larutan & Larutan & Larutan & Larutan & Stahil \\
\hline & Tekstur & Kental & Kental & Kental & Kental & Stab1l \\
\hline & $\mathrm{Bau}$ & Khas Kebiul & Khas Kebiul & Khas Kebiul & Khas Kebiul & Stabil \\
\hline \multirow{6}{*}{ F3 } & $\mathrm{pH}$ & 5 & 4 & 5 & 4 & Tidak Stabil \\
\hline & Warn & Putih & Putih & Putih & Putih & Stahil \\
\hline & warna & Kekuningan & Kekuningan & Kekuningan & Kekuningan & Stabil \\
\hline & Bentuk/ & Larutan & Larutan & Larutan & Larutan & Stabil \\
\hline & Tekstur & Kental & Kental & Kental & Kental & Stavil \\
\hline & $\mathrm{Bau}$ & Khas Kebiul & Khas Kebiul & Khas Kebiul & Khas Kebiul & Stabil \\
\hline
\end{tabular}

\section{Hasil Pengamatan Viskositas}

Uji viskositas menunjukkan

bahwa semakin banyak kandungan

ekstrak semakin meningkat pula kekentalannya. Pada pengujiaan viskositas pada emulsi yang beredar di pasaran sebesar 15 Poise dari ke-4 formula, formula 2 mendekati kekentalannya dengan emulsi yang ada dipasaran.

Tabel 5. Hasil Uji Viskositas Formulasi Sediaan Emulsi M/A Dari
Ekstrak Biji kebiul (Caesalpinia bonduc (L). Roxb.

\begin{tabular}{cc}
\hline Formulasi & Hasil Viskositas \\
\hline F0 & 11,5 poise \\
F1 & 12 poise \\
F2 & 14,5 poise \\
F3 & 24,5 poise \\
Merek-X & 15 poise \\
\hline
\end{tabular}

\section{Hasil Pengamatan Uji Sifat Alir}

Uji Sifat alir bertujuan untuk mengetahui pemindahan, penuangan, dan pengeluaran sebelum sediaan digunakan, uji sifat alir menggunakan alat dengan 
menggunakan landasan sepanjang 10 $\mathrm{cm}$ serta kemiringan landasan sebesar $45^{\circ}$ pada Uji sifat alir sediaan emulsi M/A.

Tabel 6. Hasil Uji Sifat Alir Formulasi Sediaan Emulsi M/A Dari Ekstrak Biji kebiul (Caesalpinia

\begin{tabular}{cc}
\multicolumn{2}{c}{ bonduc (L). Roxb. } \\
\hline Formulasi & Rata-rata \\
\hline F0 & 17,33 detik \\
F1 & 18,05 detik \\
F2 & 20,56 detik \\
F3 & 39,58 detik \\
Merek-X & 21,12 detik \\
\hline
\end{tabular}

Rata-rata untuk waktu sifat alir yang dibutuhkan untuk formula 1formula 3 yaitu 18,05- 40,29 detik ,sedangkan kemampuan daya tuang untuk emulsi yang beredar dipasaran yaitu 21,12 detik, dari ke-4 formula, formula 2 mendekati waktu daya tuang dengan emulsi yang ada dipasaran yaitu 20,56 detik. Semakin tinggi konsentrasi ekstrak kebiul pada sediaan emulsi, maka sifat alir yang di hasilkan semakin lama dan dalam penuangan sediaan semakin kental.

\section{Hasil Pengamatan Uji Tipe Emulsi}

Uji tipe emulsi bertujuan untuk mengetahui apakah sediaan emulsi formulasi bertipe $\mathrm{M} / \mathrm{A}$ dan $\mathrm{A} / \mathrm{M}$ menggunakan metile blue dan sudan
III. Jika penambahan metilen blueatau Sudan III tiap formulasi terjadi perubahan warna merata (terdispersi) maka tipe emulsi M/A jika tidak merata (tak terdispersi) makatipe nya $\mathrm{A} / \mathrm{M}$ (Nurdianti and Tuslinah, 2017).

Tabel 7. Hasil Uji Tipe Emulsi Formulasi Sediaan Emulsi M/A Dari Ekstrak Biji kebiul (Caesalpinia bonduc (L). Roxb)

\begin{tabular}{|c|c|c|c|}
\hline \multirow[b]{2}{*}{ Formula } & \multicolumn{2}{|c|}{ Pengujian } & \multirow{2}{*}{$\begin{array}{c}\text { Tipe } \\
\text { Emulsi }\end{array}$} \\
\hline & $\begin{array}{l}\text { Metilen } \\
\text { Blue }\end{array}$ & $\begin{array}{c}\text { Sudan III } \\
\text { A/M }\end{array}$ & \\
\hline F0 & Terdispersi & $\begin{array}{c}\text { Tidak } \\
\text { Terdispersi }\end{array}$ & $\mathrm{M} / \mathrm{A}$ \\
\hline F1 & Terdispersi & $\begin{array}{c}\text { Tidak } \\
\text { Terdispersi }\end{array}$ & $\mathrm{M} / \mathrm{A}$ \\
\hline F2 & Terdispersi & $\begin{array}{c}\text { Tidak } \\
\text { Terdispersi }\end{array}$ & $\mathrm{M} / \mathrm{A}$ \\
\hline F3 & Terdispersi & $\begin{array}{c}\text { Tidak } \\
\text { Terdispersi }\end{array}$ & $\mathrm{M} / \mathrm{A}$ \\
\hline
\end{tabular}

\section{Hasil Pengamatan Penampang}

\section{Mikroskop}

Pengamatan penampang mikroskop pada emulsi M/A yang dilakukan menunjukan bahwa tiap formula tercampur dengan baik dan terlihat homogen dikarenakan tidak terdapat buturan partikel sama dengan Sediaan merek-X yang dijadikan sebagai acuan.

\section{KESIMPULAN}

Ekstrak biji kebiul (Caesalpinia bonduc (L). Roxb) dapat diformulasi dalam bentuk 
emulsi M/A. Evaluasi sediaan emulsi memenuhi syarat uji stabilitas (uji organoleptis, uji pH), uji sifat alir,

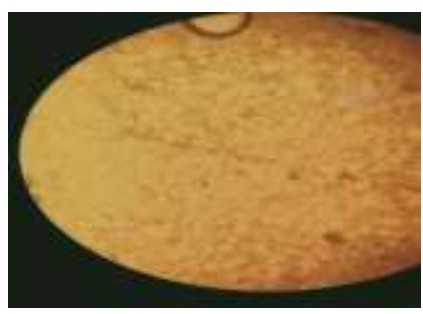

F0

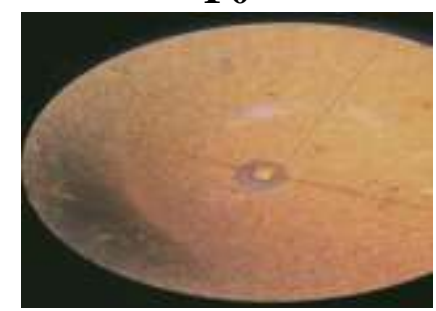

F2 uji viskositas, uji tipe emulsi, dan uji penampang mikroskop.

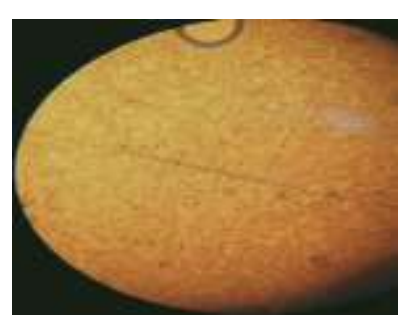

F1

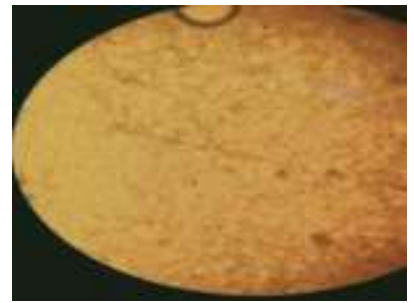

F3

Keterangan : Homogen

Gambar 1. Hasil Penampang Mikroskop Sediaan Formulasi Sediaan Emulsi M/A Dari Ekstrak Biji kebiul (Caesalpinia bonduc (L.) Roxb.)

\section{UCAPAN TERIMA KASIH}

Peneliti mengucapkan terima

kasih kepada Direktorat Riset dan

Pengabdian Masyarakat Direktorat

Jenderal Penguatan Riset dan

Pengembangan Kementrian Riset,

Teknologi, dan Pendidikan Tinggi

Atas Dana Penelitian Dosen Pemula

Sesuai dengan DIPA Deputi Bidang

Penguatan Riset dan Pengembangan

Kementerian Riset, Teknologi/

Badan Riset dan Inovasi Nasional

SP-DIPA-042.06.1.401516/2020

tanggal 12 November 2019,
Akademi Farmasi Al-Fatah

Bengkulu dan semua pihak yang membantu dalam proses penelitian.

\section{DAFTAR PUSTAKA}

Febrina dkk (2007) 'Optimasi Konsentrasi Pulvis Gummi Arabicum (PGA) sebagai Emulgator Formulasi Emulsi Ekstrak Rimpang Kunyit (Curcuma longa)',Jurnal Farmasi Udayana, 8 p. doi: 10.24843/jfu.2019.v08.i01.p.

Manoi, F. (2006) 'pembuatan dan karakteristik ekstrak kering herbal sambiloto Andrographis paniculata Nees.) Harrizul Rivai 1) , Gusmi 
Febrikesari 2) , Humaira Fadhilah 2) 1)', Jurnal Farmasi Higea, 6(1).

Manoi, F. (2015) 'Pengaruh Cara Pengeringan Terhadap Mutu Simplisia Sambiloto', Buletin Penelitian Tanaman Rempah dan Obat, 17(1), pp. 1-5. doi: 10.21082/bullittro.v17n1.2006.

Noviyanty dkk (2019) 'Fraksinasi Dan Skrining Fraksi Biji Kebiul ( Caesalpinia bonduc (L) Roxb. Dengan Metode KLT ( Kromatografi Lapis Tipis) Fraction And Screening Of Fresh Seed (Caesalpinia bonduc (L) Roxb Seeds With KLT Method ( Thin Lapis Chromatography)', Fraksinasi Dan Skrining Fraksi Biji Kebiul (Caesalpinia bonduc (L) Roxb. Dengan Metode KLT (Kromatography Lapis Tipis) Fraction, pp. 56-64.

Nugroho, I. A. 2010 (2016) 'Tumbuhan obat yang dimanfaatkan oleh battra di desa sejahtera kecamatan sukadana kabupaten kayong utara', Tumbuhan Obat yang Dimanfaatkan Oleh Batra Di Desa Sejaterah Kecamatan Sukadana Kabupaten Kayong Utara, 4, pp. 299-305.

Nurdianti, L. and Tuslinah, L. (2017) 'Uji Efektifitas Antioksidan Krim Ekstrak Etanol Daun Katuk ( Sauropus androgynus ( L ) Merr ) Terhadap DPPH', Jurnal Kesehatan Bakti Tunas Husada, 17(L).
Purwatiningrum, H. (2015) 'Formulasi Dan Uji Sifat Fisik Emulsi Minyak Jarak ( Oleum ricini ) Dengan Perbedaan Elmugator Derivat Selulosa', Politeknik Harapan Bersama, (09).

Ratnasari, D. and Handayani, R. P. (2018) 'Skrining Fitokimia Dan Uji Stabilitas Sediaan Sirup Kayu Kuning (Arcangelisia Flava) Untuk Memelihara Kesehatan Journal Of Holistic And Health Sciences', 2(1), pp. 7-13.

Rohyami, Y. (2008) 'Penentuan Kandungan Flavonoid dari Ekstrak Metanol Daging Buah Mahkota Dewa (Phaleria macrocarpa Scheff Boerl)', Logika, 58(1), pp. 1-16. doi: 10.20885/logika.vol5.iss1.art2.

Sie, J. . (2013) 'Daya antioksidan ekstrak etanol kulit buah manggis (Daya Antioksidan Ekstrak Etanol Kulit Manggis (Garcinia mangostana Linn.) Hasil Pengadukan Dan RefluxA, 2(1), pp. 1-10.

Sopianti dkk (2017) 'Prosiding Seminar Nasional Herbal Medicine 2017'.

Wedana, J. S. et al. (2009) 'Optimasi Komposisi Span ® 60 dan Tween ${ }^{\circledR} \quad 80 \quad$ sebagai Emulgator terhadap Stabilitas Fisik dalam Formulasi Cold Cream Ekstrak Kulit Buah Manggis (', Jurnal Farmasi Udayana, 8, pp. 91-95. 